\title{
A EXPERIÊNCIA EM EXTENSÃO NO PET MATEMÁTICA DA UFSC E AS OLIMPÍADAS DE MATEMÁTICA
}

\author{
José Luiz Rosa Pinho'
}

\begin{abstract}
Resumo
Neste trabalho, relatamos a nossa experiência de treze anos em projetos de extensão na tutoria do programa PET do Curso de Matemática da UFSC. Quatro projetos de maior relevância são aqui brevemente apresentados, além de dois outros, atualmente considerados como Projetos Institucionais Permanentes da UFSC. Esses dois projetos são a Olimpíada Regional de Matemática de Santa Catarina (ORM) e a Revista da ORM, que são aqui descritos com mais detalhes. Em especial, discutimos os aspectos criativos necessários à resolução dos problemas olímpicos de matemática e ressaltamos a importância do desenvolvimento do raciocínio crítico na formação de nossos estudantes do ensino básico.
\end{abstract}

Palavras-chave: Olimpíadas de matemática. PET Matemática. Projetos de extensão.

\section{THE OUTREACH EXPERIENCE OF UFSC'S PET MATEMÁTICA AND THE MATH OLYMPICS}

\begin{abstract}
In this work we describe our thirteen years of experience in outreach projects as the tutor of the PET program of Mathematics at UFSC. Four projects of great relevance are briefly presented here, together with two others, which are considered presently as UFSC Permanent Institutional Projects. Those two projects are the Regional Mathematics Olympiad of Santa Catarina (ORM) and the ORM Magazine, which are described here in more details. Particularly, we discuss the necessary creativity to the resolution of mathematics olympic problems and we give special emphasis to the relevance of the critical reasoning development of our basic and high school students.
\end{abstract}

Keywords : Mathematics olympiad. PET Mathematics. Outreach projects.

\footnotetext{
${ }^{1}$ Graduado em Química pela Universidade Federal do Rio de Janeiro (1970) e mestre em Matemática pela Associação Instituto Nacional de Matemática Pura e Aplicada (1980). Professor Adjunto IV da Universidade Federal de Santa Catarina (Florianópolis), é Tutor do PET Matemática da UFSC e Coordenador das Olimpíadas Brasileira e Regional de Matemática em Santa Catarina."
} 


\section{INTRODUÇÃO}

Como tutor do PET $^{2}$ Matemática da UFSC Desde 1996, coordenei e coordeno diversos projetos e atividades de extensão realizados pelo grupo, com a eventual participação de outros alunos do curso e professores do Departamento de Matemática da UFSC. Relatarei brevemente aqui alguns desses projetos, em particular aqueles que maior impacto tiveram na comunidade acadêmica ou junto à comunidade não universitária. $\mathrm{O}$ grupo atuou, e atua, em geral, em projetos de extensão na área de Educação. Em especial, dedicarei uma grande parte deste artigo para descrever e ressaltar a importância (na minha visão) do projeto mais antigo e permanente do grupo: as Olimpíadas de Matemática. Atividades de extensão de curta duração, tais como promoção de palestras, organização e realização de minicursos, não serão abordadas aqui. Cumpre ressaltar que, nos relatos dos projetos, será usada a primeira pessoa do plural, não por formalismo ou falsa modéstia, mas em razão de que o trabalho realizado foi, e tem sido sempre, um trabalho em equipe, com iniciativa e entusiasmo dos alunos que participaram e participam do programa PET e também aqueles com bolsa de extensão.

O projeto de extensão mais antigo do PET ocorreu em 1997 com a presença do Professor Visitante Recorrente, uma figura que era contemplada no programa durante a "era" CAPES. De 2004 a 2006, realizamos os Encontros de Matemática Universitária e, atualmente, o Projeto Gauss e as FERMAT são projetos que já têm, pelo menos, dois anos de duração. As Olimpíadas de Matemática serão relatadas, como foi dito acima, em uma seção à parte que envolve, mais especificamente, a Olimpiada Regional de Matemática de Santa Catarina e um projeto paralelo e de apoio que é a Revista da Olimpíada Regional de Matemática de Santa Catarina.

\section{Quatro projetos de extensão}

Em 1996, eu havia feito um convite para o professor André Nachbin, do Instituto Nacional de Matemática Pura e Aplicada (IMPA) do Rio de Janeiro, e que eu conhecia desde 1985, para que visitasse a UFSC. Naquela época, a CAPES permitia, e estimulava que qualquer grupo PET convidasse um professor de outra instituição para participar de atividades junto ao grupo por um período mínimo de 15 dias. Tal professor era denominado Professor

\footnotetext{
${ }^{2}$ O grupo PET (Programa de Educação Tutorial - MEC/SESu, antigamente denominado Programa Especial de Treinamento - MEC/CAPES) Matemática, é formado por 12 alunos do Curso de Matemática que, sob a coordenação e orientação de um professor tutor, realizam atividades de ensino, pesquisa e extensão.
} 
Visitante Recorrente e essa foi a oportunidade que vi de concretizar aquele convite. O problema que ocorria, em geral, com esse tipo de convite é que, para o professor convidado, não se tratava de um convite para uma palestra em um congresso de quatro ou cinco dias, nem de uma licença sabática. O professor convidado teria que visitar o grupo durante o período letivo, comum a todas as universidades brasileiras, tendo que deixar de lado suas próprias turmas de alunos durante o período da visita. Acontece que, no IMPA, um centro de pesquisa e de pós-graduação em matemática de excelência no país, os pesquisadores têm, diferentemente das universidades brasileiras, a possibilidade de se dedicar mais à pesquisa e menos às aulas em alguns semestres. Isso permitia que o pesquisador pudesse fazer, caso quisesse, uma pausa, ou um rearranjo em seu cronograma de pesquisa, para se ausentar por um período de duas ou mais semanas. Mas o André não pôde me dar uma resposta ao convite imediatamente. Em setembro de 1996, duas alunas do nosso PET que participaram do XIX CNMAC em Goiânia, GO, reforçaram o convite ao André, que lá estava presente e, graças ao empenho dessas alunas, ficou acertado que ele viria em 1997. Passamos, então, a organizar essa visita, que, de fato, ocorreu em abril de 1997, com uma programação variada que constou do minicurso Introdução à Modelagem Matemática e Computação Científica, com seis dias de duração, de duas palestras, de horários para atendimento aos interessados na área, e até mesmo de uma programação social com uma caminhada do grupo, do professor visitante e de professores do departamento pela trilha da Lagoinha do Leste. O minicurso, inicialmente planejado para uma plateia de alunos do Curso de Matemática, contou com a presença de, aproximadamente, 50 pessoas e, dentre essas, alunos de pós-graduação de matemática e de engenharias, e professores do Departamento de Matemática e de outros departamentos da UFSC.

O I Encontro de Matemática Universitária foi idealizado em 2004 por uma aluna bolsista do PET. No início havia apenas a ideia de realizar um pequeno congresso voltado para os estudantes universitários da UFSC, mas não tínhamos clareza de como deveria ser esse encontro. Sugeri que convidássemos alguns docentes do Departamento de Matemática da UFSC e de outras instituições do país, e que, pelo menos para a abertura e para o encerramento do Encontro contássemos com a presença de pesquisadores matemáticos de projeção nacional e internacional. O encontro deveria ser voltado para os estudantes universitários de Santa Catarina e da região sul do país, de maneira a oportunizar o contato desses estudantes com aqueles pesquisadores. Desde o início, contamos com um aliado inestimável, nosso colega professor Clóvis Gonzaga, ele mesmo, um matemático de projeção 
internacional na área de otimização, que nos ajudou a financiar parte do Encontro através do Instituto do Milênio - Avanço Global e Integrado da Matemática Brasileira (http://milenio.impa.br/). A outra parte do I Encontro foi financiada pela própria UFSC, através de várias Pró-Reitorias da nossa universidade. O I Encontro ocorreu em novembro de 2004 e, graças à qualidade anunciada dos palestrantes e à divulgação eficaz, contou com a presença de 16 palestrantes (oito da UFSC e oito de outras instituições) e de 200 estudantes universitários da região sul, de São Paulo e do Rio de Janeiro. O Encontro foi totalmente organizado pelo PET Matemática da UFSC, desde os convites aos palestrantes, inscrições dos participantes, elaboração de material distribuído (crachás, pastas, camisetas) e hospedagem para os estudantes (incluídos na inscrição) e coffe break. Os Encontros subsequentes mantiveram esse nível de qualidade e organização, com uma procura crescente dos estudantes. Citarei aqui apenas os nomes dos ilustres palestrantes nas aberturas e encerramentos dos três Encontros que foram realizados:

I Encontro (2004)

Abertura - Prof. Clóvis Caesar Gonzaga (UFSC)

Encerramento - Prof. Djairo Guedes de Figueiredo (UNICAMP)

\title{
II Encontro (2005)
}

Abertura - Prof. Jacob Palis Junior (IMPA)

Encerramento - Prof. Newton Carneiro da Costa (UFSC)

\section{Encontro (2006)}

\author{
Abertura - Prof. Marcelo Viana (IMPA) \\ Encerramento - Prof. Paulo Cordaro (USP)
}

O comentário do professor Jacob Palis Junior, presidente da Academia Brasileira de Ciências e do Instituto do Milênio, de que ele "nunca havia visto e participado de um encontro de estudantes com aquela organização e qualidade" foi, para nós, além de um grande elogio, uma certeza de que o nosso trabalho se desenvolvia de maneira certa. Na página citada do Instituto do Milênio podem ser encontradas as programações e os relatórios desses encontros. 

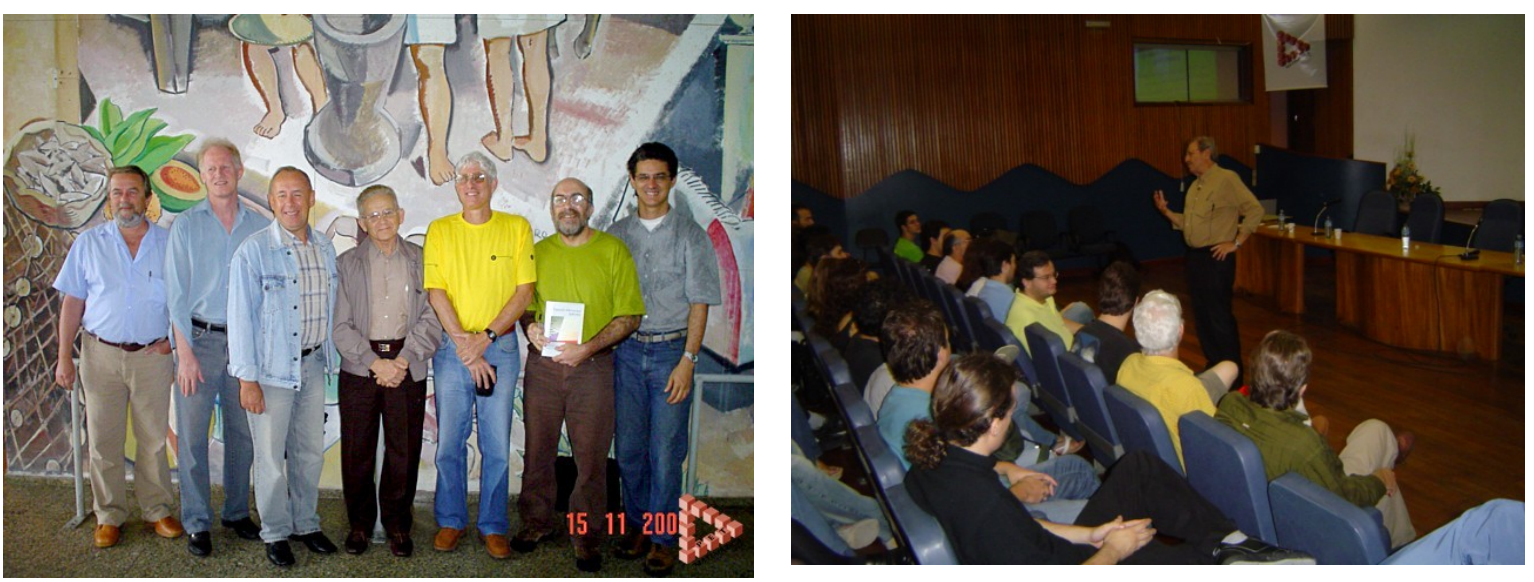

Fotos 1 e 2 - Os professores Clóvis Caesar Gonzaga e Djairo Guedes de Figueiredo no I Encontro, juntamente com professores da UFSC, e a palestra do professor Jacob Palis Junior na abertura do II Encontro.

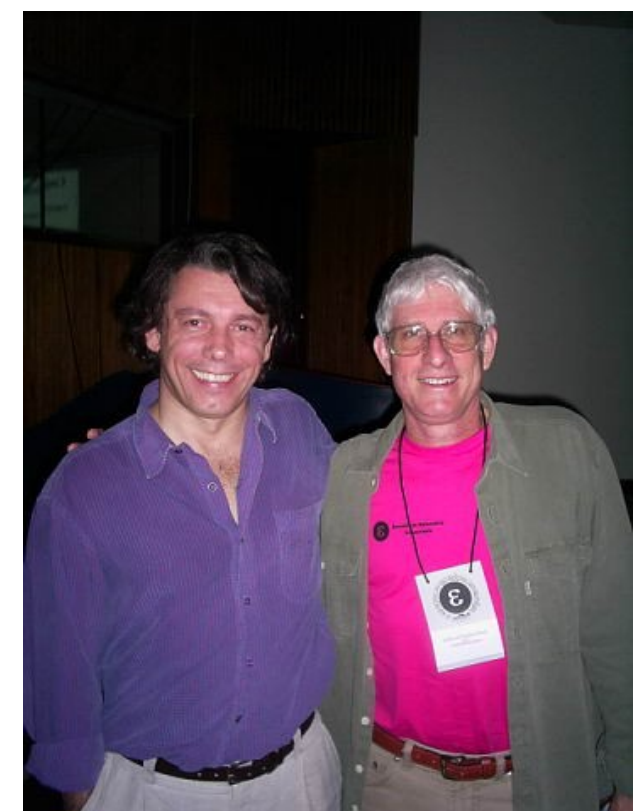

Foto 3 - O professor Marcelo Viana e o autor na abertura do III Encontro

O Projeto Gauss começou em 2008 por iniciativa dos bolsistas do PET. O projeto consiste em oferecer aulas gratuitas de matemática sobre todo o conteúdo de todo o ensino médio para alunos das escolas públicas e, a partir do segundo semestre de 2010, também para alunos de escolas particulares, com ênfase na resolução de problemas de vestibular. A ideia é auxiliar os estudantes que estão prestes a prestar o vestibular e que tenham dificuldades com matemática. A programação anual das aulas é divulgada no início do ano de modo que os estudantes possam comparecer às aulas dos assuntos que mais têm dúvidas. A frequência tem 
sido variável durante o ano, mas isso é de se esperar considerando que os estudantes escolhem as aulas dos assuntos mais necessários para cada um deles.

A Feira Estudantil Redescobrindo a Matemática (FERMAT) também foi idealizada por uma aluna bolsista do PET em 2008. É uma atividade de extensão que ocorre em apenas um dia por ano, mas que demanda uma preparação de, pelo menos, dois meses que antecedem o evento. O projeto é realizado em parceria com o SESC Estreito e o Laboratório de Estudos de Matemática e Tecnologia (LEMAT) do Departamento de Matemática da UFSC. A FERMAT é uma feira onde a matemática é apresentada através de jogos e curiosidades de forma a cativar os estudantes do ensino básico. Uma média de 20 escolas tem participado a cada ano, com a presença de 800 alunos por ano. Para atender a todo esse pessoal, os alunos do PET Matemática desenvolvem os temas a serem abordados e organizam a realização da feira convidando os bolsistas do LEMAT, monitores do SESC e outros alunos do Curso de Matemática. O Departamento de Apoio a Eventos cede o hall e algumas salas do Centro de Cultura e Eventos da UFSC. Em torno de 40 monitores, a maioria alunos do curso, participam da feira. O nome da feira foi idealizado de forma a permitir que sua sigla fosse FERMAT, que é o nome de um famoso matemático francês do século XVII (Pierre de Fermat). Na página do evento está escrito:

Pierre de Fermat (1601-1665) foi um matemático francês de grandes contribuições. Nunca teve a matemática como uma atividade formal e, por isso, era considerado um amador. No entanto, foi um dos pioneiros da Geometria Analítica, contribuiu para o desenvolvimento do Cálculo e foi o precursor da Moderna Teoria dos Números. Além disso, deixou um teorema que demorou mais de 300 anos para ser demonstrado. Atualmente conhecido como o Último Teorema de Fermat, este resultado foi provado em 1994 pelo matemático britânico Andrew Wiles. (FEIRA ESTUDANTIL REDESCOBRINDO A MATEMÁTICA, 2008). 


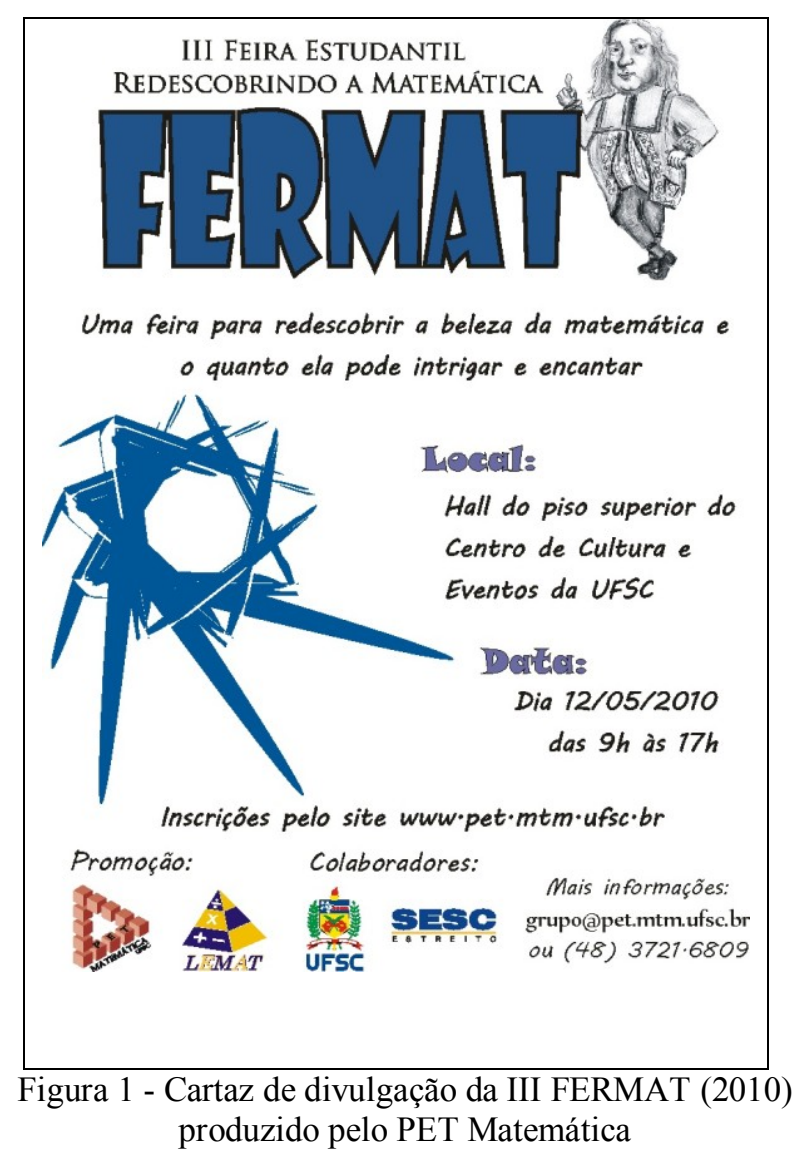

\section{Matemática e as Olimpíadas de Matemática}

"Você é um matemático? Então você trabalha com números". Essa frase, embora parcialmente verdadeira, normalmente citada por pessoas leigas, não define nem de longe o que é um matemático ou o que faz um matemático. A questão central talvez não seja definir o que é um matemático e sim perguntar: o que é matemática? O excelente texto de Courant e Robbins (COURANT; ROBBINS, 1996) tenta responder a essa pergunta, infelizmente, para os não leigos. Costumo fazer essa pergunta para os meus alunos, quando leciono alguma disciplina de primeira fase, e geralmente proponho aos calouros alguns problemas provocativos para pensar durante o semestre. Um desses problemas é o chamado "Problema de Sylvester", que pode ser enunciado assim: dados n pontos no plano $(n \geq 2)$, não todos na mesma reta, provar que existe uma reta que passa por exatamente dois desses pontos.

Esse é um problema que poderíamos classificar como do tipo "olímpico", dadas a criatividade necessária para sua resolução e a não exigência de um grande conhecimento matemático para resolvê-lo. Observe que o problema pede para provar a existência de tal reta, 
qualquer que seja a configuração dos n pontos (e há uma infinidade delas) desde que esses pontos sejam não colineares. A hipótese crítica deste problema é que a quantidade de pontos considerados é finita e o problema exige, para sua resolução, não mais do que o conhecimento básico de geometria elementar.

Outro problema curioso é o seguinte: considere um número irracional qualquer (por exemplo, o número $\pi$ ) em sua representação decimal (obviamente com parte decimal não finita e não periódica). Mostre que, para qualquer natural n, existe uma sequência de $n$ casas decimais consecutivas, na parte decimal do número, que irá se repetir exatamente em outro lugar dessa parte decimal.

Por exemplo, suponha $n=3$ e seja o número $\pi$. Abaixo temos uma aproximação para $\pi$ com 214 casas decimais e as sequências 628 e 117 que se repetem uma vez (grifadas):

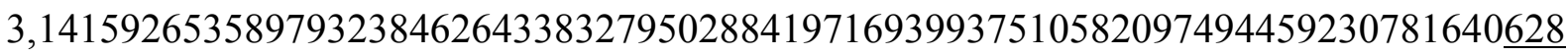

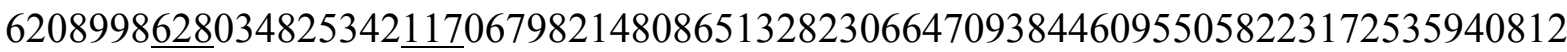
$8481 \underline{1174502841027019385211055596446229489549303819644288109756659}$

Uma simples observação desse exemplo deve ser suficiente para se perceber por que a afirmação é verdadeira (de fato, o princípio das gavetas de Dirichlet permite prová-la), mas o problema soa como fantástico se imaginarmos n igual a $10^{100}$. Estamos afirmando que existe essa quantidade de dígitos consecutivos na parte decimal de $\pi$ que irá aparecer novamente e exatamente na mesma ordem!

"Provocar" os alunos com problemas "não convencionais", estimulando-os a resolvêlos ou, pelo menos, entendê-los, é algo que acredito que seja um importante passo para a compreensão do que é matemática. Para um matemático, ter problemas na cabeça é mais interessante do que ter soluções à mão. Isso nos remete ao ano de 1900, em Paris, quando o matemático David Hilbert apresentou, no II Congresso Internacional de Matemáticos, uma lista de 23 problemas que, segundo ele próprio, iriam ocupar as mentes dos matemáticos durante o século XX (HILBERT, 1902). Pois bem, o século XX passou e, até hoje, alguns (poucos) desses problemas não foram resolvidos, como por exemplo, o problema 8 que, na verdade são duas questões relacionadas a números primos. Uma delas é a hipótese de Riemann, que também é um dos sete problemas do milênio (um projeto do Clay Mathematics Institute, Cambridge, Massachusetts), e a outra é a conjectura de Goldbach, cujo enunciado, compreensível para qualquer pessoa com conhecimento básico de matemática, diz: todo 
número par maior ou igual a 4 é a soma de dois números primos (por exemplo, $4=2+2$, $6=3+3,8=3+5,12=5+7,100=3+97)$. Para uma pessoa leiga, um problema matemático avançado ou de ponta soará como algo completamente obscuro e um problema de enunciado simples de se compreender soará como algo completamente ridículo. Isso porque essa pessoa possivelmente perguntará: para que serve isso? Matemáticos sempre fizeram piadas a respeito da importância de sua área de estudo. $\mathrm{O}$ fato é que, apenas compreender o enunciado de um problema não é suficiente para compreender o significado desse problema dentro de uma teoria na qual se insere esse problema, e isso requer, é claro, conhecer mais matemática. Essa visão "utilitarista" do "para que serve?" é, em parte, compreensível, pois espera-se que cientistas e estudiosos estejam sendo pagos para fazer algo prático, útil e importante para uma nação ou para a humanidade. Porém, é uma grande pretensão achar que julgar o que é útil e importante, agora ou para o futuro, é uma coisa simples. Nossos jovens estudantes têm dificuldade de escolher suas carreiras, em parte, pelo retorno econômico que a profissão lhes dará e, em parte, por não saberem o que significam essas carreiras. Todos eles sabem, ou pensam saber, o que um médico ou um dentista fazem, porém não têm uma ideia precisa do que fazem certos tipos de engenheiros e não tem ideia nenhuma do que é um físico ou um matemático. Um físico é um algum tipo de louco ou gênio, algum Einstein; e um matemático? Bem, um matemático é aquele que faz contas, ou aquele que é como seus professores de matemática sempre foram. E matemática é aquela matéria difícil (opinião muitas vezes passada "de pais para filhos"), chata e enfadonha. É incrível que, sendo a matemática e o nosso idioma as únicas matérias estudadas desde o início da nossa vida escolar até o final do ensino básico (fundamental e médio), uma grande parte dos estudantes tenha uma opinião tão negativa a respeito dela. Afinal, o que é matemática?

Para começar, matemática não é considerada uma ciência porque ela é idealizada, é platônica. Segundo Platão, o verdadeiro conhecimento só pode ser adquirido pelo puro pensamento, e toda a matemática, dos gregos até hoje, vem sendo feita desta forma, com teorias desenvolvidas através de teoremas com o uso de lógica. Dessa forma, parece incrível, e até mesmo incompreensível, a aplicabilidade da matemática nas ciências naturais. O prêmio Nobel de física de 1963, Eugene Wigner, considera esse aspecto da matemática, observando que a estrutura matemática de uma teoria física leva a um desenvolvimento dessa mesma teoria e até mesmo à possibilidade de predizer resultados empíricos (WIGNER, 1960).

Eu poderia então dar a resposta utilitarista à pergunta sobre o que é matemática dizendo: sem matemática não existiriam carros e aviões, não se fariam cirurgias, não haveria 
aparelhos para exames médicos, etc. Em suma, sem matemática o mundo seria bem diferente do que é hoje em dia. Dar uma resposta àquela pergunta não é uma tarefa simples, haja vista a obra de Courant e Robbins (1996); no entanto, prefiro uma resposta mais "estrutural", se bem que incompleta qual seja: matemática - ou fazer matemática - é a capacidade de demonstrar a existência de uma solução de um problema, ou de um objeto matemático, sem ter que exibila, é a capacidade de mostrar que um problema tem solução sem ter que resolvê-lo, ou a capacidade de mostrar que um problema não tem solução sem ter que tentar (infinitamente) resolvê-lo. Matemática não tem a ver somente com números ou com contas, não tem a ver somente com aplicações. Matemática tem a ver com todo o conhecimento, com a essência de tudo.

O que tem a ver o que foi escrito acima com uma olimpíada de matemática? Primeiramente, é necessário saber o que é uma olimpíada de matemática. Uma olimpíada de matemática é uma competição, normalmente individual, de resolução de problemas de matemática, problemas esses que são não convencionais, no sentido de que não são encontrados em livros, e que exigem mais criatividade e imaginação do que o conhecimento de fórmulas ou de teorias. Elas ocorrem para estudantes desde o nível básico (fundamental e médio) até o nível universitário.

O lado competitivo das olimpíadas fornece, como em todas as olimpíadas, um estímulo saudável à resolução dos problemas. Muitos pedagogos vêm nisso um aspecto negativo no ambiente escolar. Essa é uma opinião da qual não compartilho. Competição à parte, vamos nos concentrar nos problemas de olimpíadas, ou problemas olímpicos. Pensar que resolver um problema de matemática se limita a usar fórmulas, acessando-as como se tivéssemos uma prateleira cheia delas, e que bastasse retirá-las e depois misturá-las convenientemente, é ter uma visão muito superficial do que é resolver um problema matemático. Na França, um país com grande tradição matemática, não é permitido aos alunos resolverem uma equação de segundo grau usando a fórmula de Baskhara. Eles devem usar um método de resolução como completar quadrados. Criatividade na resolução de problemas matemáticos significa o uso de ideias originais e também a associação de métodos, ou técnicas - não fórmulas - de resolução dos problemas. Isso é o que, essencialmente, um pesquisador em matemática utiliza no desenvolvimento de sua pesquisa. O que é um método de resolução de um problema? Ao matemático húngaro George Pólya (Pólya György), famoso por seus escritos sobre resolução de problemas, juntamente com seu colega Gabor 
Szego, é atribuída a seguinte frase: "Uma ideia que pode ser usada uma vez é um truque. Se ela pode ser usada mais de uma vez torna-se um método."

Um raciocínio olímpico de resolução pode ser exemplificado através do seguinte problema (que não é olímpico, pois é muito conhecido): encontrar a soma dos números naturais de 1 até 100 .

Esse é um problema que é facilmente resolvido por alunos empregando a fórmula da soma de números em progressão aritmética. É um fato conhecido de que o jovem Gauss (Carl Friedrich Gauss) resolveu problema semelhante, quando era aluno do ensino fundamental, por uma exigência de seu professor a todos os alunos na sala. Isso quando tinha oito anos de idade e em poucos minutos (sem conhecer a fórmula de Baskhara).

A ideia para resolver o problema é a seguinte: observe que $1+100=101$, que $2+99=101$, que $3+98=101, \ldots$, que $50+51=101$. Portanto, somar de 1 a 100 é o mesmo que efetuar uma soma de 50 parcelas iguais a 101. Isso nos dá 50 x $101=5050$.

Outro problema que exemplifica um raciocínio olímpico é o seguinte:

Escrever $a$ soma $S=\frac{1}{1 \cdot 2}+\frac{1}{2 \cdot 3}+\frac{1}{3 \cdot 4}+\cdots+\frac{1}{n(n+1)}$ em uma expressão simples em função de $n$.

Este problema pode ser resolvido observando-se que $\frac{1}{n(n+1)}=\frac{1}{n}-\frac{1}{n+1}$. Desta forma, teremos que $\frac{1}{1 \cdot 2}=\frac{1}{1}-\frac{1}{2}$, que $\frac{1}{2 \cdot 3}=\frac{1}{2}-\frac{1}{3}$ etc. Assim, a soma transforma-se em:

$S=\left(\frac{1}{1}-\frac{1}{2}\right)+\left(\frac{1}{2}-\frac{1}{3}\right)+\left(\frac{1}{3}-\frac{1}{4}\right)+\cdots\left(\frac{1}{n}-\frac{1}{n+1}\right)=1+\left(-\frac{1}{2}+\frac{1}{2}\right)+\left(-\frac{1}{3}+\frac{1}{3}\right)+\cdots-\frac{1}{n+1}=$

$=1+\frac{1}{n+1}=\frac{n}{n+1}$, que é a resposta procurada.

Essa última ideia não é um simples truque, mas um método, segundo Pólya, pois é usada na soma das chamadas séries telescópicas, e é usada na técnica de integração por frações parciais, ambos vistos em Cálculo.

Olimpíadas de matemática existiam na Hungria desde o fim do século XIX. Em 1959, foi realizada oficialmente a primeira International Mathematical Olympiad (IMO). Em 1979, 
o Brasil passa a participar da IMO e a realizar a Olimpíada Brasileira de Matemática (OBM). As premiações nas olimpíadas de matemática são, tradicionalmente, feitas com medalhas de ouro, prata ou bronze, e com menções honrosas. A partir dos resultados da OBM, são selecionados seis estudantes para compor a equipe que irá representar o Brasil na IMO. O Brasil já obteve 8 medalhas de ouro, 23 de prata e 59 de bronze nessa competição. Em 1998, a Sociedade Brasileira de Matemática (SBM) resolveu estimular a realização de olimpíadas regionais como forma de aumentar a participação de estudantes na OBM. Para que isso pudesse ser realizado, foram escolhidos coordenadores regionais (em geral por estado) e foi disponibilizado um auxílio financeiro, através do CNPq (uma vez pelo Instituto do Milênio), para os gastos com essas olimpíadas.

Iniciamos nossa olimpíada, a Olimpíada Regional de Matemática de Santa Catarina (ORM), no mesmo ano de 1998 (antes desse ano, o meu colega do Departamento de Matemática e então tutor do PET Matemática, Licio Hernanes Bezerra, já selecionava alguns alunos do ensino médio para participar da OBM), sendo eu próprio (já na tutoria do PET) e o professor Licio coordenadores regionais. A ORM tem características bem especiais. Dela participam professores do Departamento de Matemática, os bolsistas do PET, bolsistas de extensão, alunos com outros tipos de bolsa (permanência, estágio) e alunos voluntários, todos do Curso de Matemática da UFSC. Toda a organização é realizada pelos bolsistas de extensão e outros bolsistas, que participam de todas as etapas da olimpíada. Os bolsistas do PET atualmente participam dos treinamentos (são realizadas 10 semanas de treinamentos na UFSC, em que são discutidos problemas de olimpíadas anteriores, os métodos de resolução e conteúdos correspondentes), da aplicação e da correção das provas. Os professores participam dos treinamentos, da elaboração e da correção das provas. Na correção das provas, cada questão é corrigida duplamente, uma vez por um bolsista e uma vez por um professor, e os dois confrontam depois suas correções. Os professores que participam ou já participaram são: Carmem Suzane Comitre Gimenez, Danilo Royer, Eliezer Batista, Licio Hernanes Bezerra, Nereu Estanislau Burin, Waldir Quandt (falecido) e William Glenn Whitley (falecido). Não nomearei aqui os alunos envolvidos por serem muitos, nesses treze anos de ORM, mas posso dizer que não haveria esse projeto de extensão sem a participação deles. A ORM é um projeto de extensão dos bolsistas do PET Matemática, em conjunto com os outros bolsistas. Creio que não há no Brasil nenhuma olimpíada regional com essa estrutura de organização. A integração entre professores do Departamento de Matemática, alunos do Curso de Matemática e professores e estudantes das escolas torna o projeto único. A aplicação das provas da segunda 
fase (a ORM é realizada em duas fases) em polos no estado tem sido feita desde 2002 como meio de facilitar a participação dos estudantes classificados para essa fase. A ORM tem página própria na internet, associada à página do PET Matemática da UFSC. Naquela página, podem ser encontrados todos os treinamentos com resoluções e informações gerais. Uma novidade neste ano é que videoaulas de treinamento estão também disponíveis na página, gravadas pelos alunos do PET e bolsistas de extensão e pelos professores participantes do projeto, e produzidas no Laboratório de Ensino a Distância (LAED) do Departamento de Matemática. Os dados relativos às ORM podem ser encontrados em um artigo que anteriormente escrevemos para esta revista (MATTOS et al., 2004) e em um artigo de minhas alunas do PET (SOUZA; SCHNEIDER, 2010), mas podemos dizer que, em média, 8000 alunos participam das provas da primeira fase, compreendendo 150 a 200 escolas de, aproximadamente, 90 municípios do estado. São premiados, no final, em torno de 80 estudantes, em uma cerimônia que conta com a presença de autoridades da UFSC na composição da mesa, dos familiares dos estudantes, de professores e diretores das escolas, de professores do Departamento de Matemática e alunos do Curso, totalizando 400 a 600 pessoas. As premiações são, como em todas as olimpíadas, na forma de medalhas. A partir de 2006, foi instituído o prêmio William Glenn Whitley, em homenagem ao nosso colega professor do Departamento de Matemática que tanto fez pela ORM, para aquele estudante que obtivesse a maior pontuação na olimpíada em cada ano. É preciso dizer que o apoio da UFSC tem sido de vital importância para este projeto, com auxílio financeiro e auxílio em bolsas para alunos do Curso. Em particular, muito devemos à Pró-Reitoria de Pesquisa e Extensão (PRPE), através do seu Departamento de Projetos de Extensão (DPE), e a outras PróReitorias. Um projeto paralelo, a Revista da Olimpíada Regional de Matemática de Santa Catarina, começou a ser realizado em 2003. Nessa revista, editada anualmente e inteiramente produzida pelo PET Matemática e bolsistas de extensão, são publicadas as provas da segunda fase da ORM, com soluções, do ano anterior, juntamente com artigos sobre matemática e olimpíadas de matemática.

Os objetivos da ORM são: descobrir jovens talentos em matemática; estimular nos estudantes o gosto pelos estudos em matemática; desenvolver a criatividade e o espírito crítico nestes estudantes; estabelecer e manter um vínculo entre a UFSC e as escolas públicas e particulares do Estado de Santa Catarina; proporcionar, através dessa atividade, uma melhoria no ensino da matemática nas escolas; permitir que os alunos do Curso de Matemática da UFSC travem contato, desde cedo, com os estudantes e professores das 
escolas do ensino fundamental e médio; abrir uma porta, na forma de estágios não obrigatórios, para que os alunos do Curso de Matemática da UFSC possam atuar nas escolas com aulas de reforço e preparação para as Olimpíadas, contribuindo assim para mais uma atividade na graduação; divulgar o Curso de Matemática da UFSC, permitindo uma escolha consciente de carreira por parte dos estudantes no ingresso na universidade, contribuindo para uma diminuição da evasão neste curso; e criar uma cultura de olimpíadas de matemática em todo o Estado de Santa Catarina. Esses objetivos têm sido alcançados com maior ou menor intensidade. Quanto à descoberta de jovens talentos em matemática, podemos dizer que a ORM já resultou em premiações de estudantes catarinenses em olimpíadas nacionais e internacionais. É de se destacar a participação na IMO dos estudantes Renan Henrique Finder, de Joinville, em 2008 e 2009, com medalhas de prata, e do estudante Gustavo Lisbôa Empinotti, de Florianópolis, em 2010, com medalha de bronze.

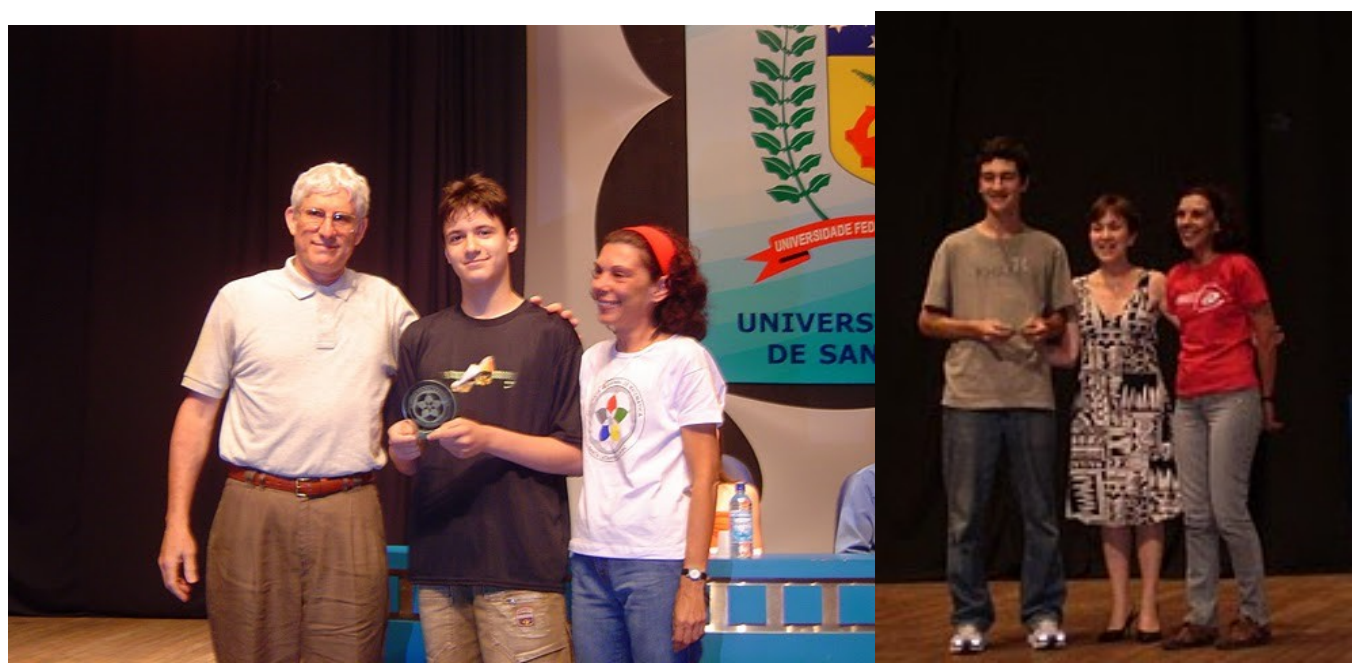

Fotos 4 e 5 - O estudante Renan Henrique Finder recebendo o prêmio William Glenn Whitley na IX ORM em 2006 das mãos do autor e da professora Carmem Suzane C. Gimenez; e o estudante Gustavo Lisbôa Empinotti recebendo o mesmo prêmio na XI ORM em 2008, das mãos da professora Mônica Aparecida Aguiar dos Santos, da PRPE, e da professora Carmem Suzane C. Gimenez.

Quanto aos objetivos relativos ao ensino de matemática nas escolas, podemos dizer que eles têm sido lentamente alcançados: professores já realizam treinamentos em suas escolas e participam dos Encontros da ORM, anualmente realizados na UFSC e voltados para esses professores. O desafio ainda é grande, pois criar uma cultura de olimpíadas nas escolas, incentivando a discussão de problemas não convencionais é uma questão de mudar a mentalidade e a postura frente à matemática e de compreender realmente o que é matemática. 


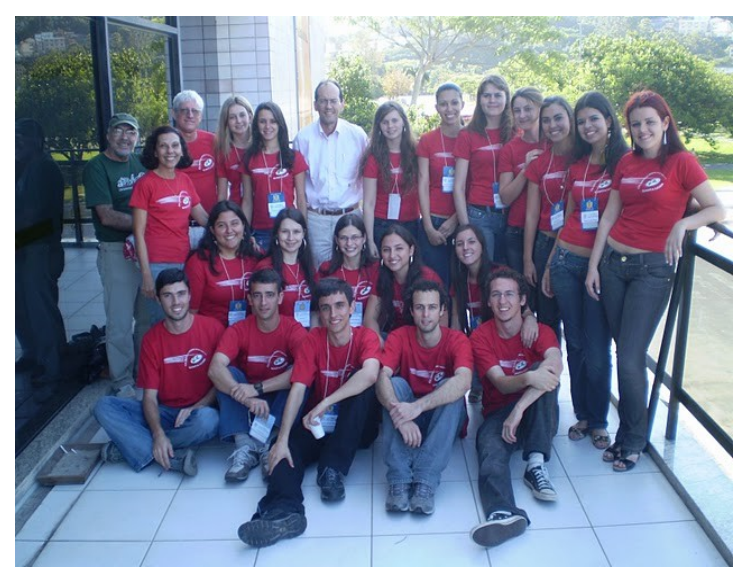

Foto 6 - A equipe da ORM junto com o Reitor, professor Álvaro Toubes Prata, na cerimônia da XI ORM em 2008.

\section{DEDICATÓRIA}

Este artigo é dedicado a todos os meus alunos do PET Matemática e bolsistas e voluntários da ORM. Sem sua dedicação, entusiasmo e bravura os projetos de extensão do PET não existiriam nem teriam sucesso.

\section{REFERÊNCIAS}

COURANT, R., ROBBINS, H. What is Mathematics? 2. ed. New York: Oxford University Press, 1996.

HILBERT, D. Mathematical Problems. Bulletin of the American Mathematical Society, Providence, v. 8, n. 2, p. 437-479, jul. 1902.

MATTOS, A.D. et al. V Olimpíada Regional de Matemática de Santa Catarina, Extensio: Revista Eletrônica de Extensão, Florianópolis, v. 1, n. 0, maio 2004.

Feira Estudantil Redescobrindo a Matemática. PET Matemática. UFSC. Disponível em: $<$ http://pet.mtm.ufsc.br/iifermat.html $>$. Acesso em 20 de jul. de 2010.

SOUZA, T. S.; SCHNEIDER, R. M. A Olimpíada Regional de Matemática de Santa Catarina desde a origem. Revista da Olimpíada Regional de Matemática, Florianópolis, n. 8, 2010. A ser publicado.

WIGNER, E. The Unreasonable Effectiveness of mathematics in the Natural Sciences. Communications in Pure and Applied mathematics, New York, v. 13, n. 1, p. 1-14, fev. 1960. 